\title{
METHODICAL APPROACH FOR PROCESS SELECTION IN ADDITIVE MANUFACTURING
}

\author{
Wortmann, Nadine (1); Jürgenhake, Christoph (2); Seidenberg, Tobias (2); Dumitrescu, Roman \\ (2); Krause, Dieter (1)
}

1: Technische Universität Hamburg Produktentwicklung und Konstruktionstechnik; 2: Fraunhofer Research Institute for Mechatronic Systems Design IEM

\begin{abstract}
In recent years, rapid technical progress has led to additive manufacturing achieving a high degree of technological maturity that enables a broad range of applications. This is reinforced in particular by the advantages of the technology, such as the production of complex components, smaller quantities and fast reaction times. However, a lack of knowledge of the various process techniques, such as insufficient potential assessment, specific design guidelines or even of process restrictions, often lead to different errors.

This paper presents a methodological approach to support designers in the manufacturing process selection of specific parts at an early stage of product development. In a four-stage procedure, potential part candidates are first identified and part classes formed on the basis of characteristics. Building on this, AM thinking is to be stimulated, for example, with the aid of design guidelines. A comparison between conventionally and additively manufactured parts can be made using a simplified cost model. The results are incorporated into a process model that supports companies in the systematic selection of manufacturing processes.
\end{abstract}

Keywords: Additive Manufacturing, Design methodology, Integrated product development

Contact:

Seidenberg, Tobias

Fraunhofer Research Institute for Mechatronic Systems Design IEM

Product Engineering

Germany

tobias.seidenberg@iem.fraunhofer.de

Cite this article: Wortmann, N., Jürgenhake, C., Seidenberg, T., Dumitrescu, R., Krause, D. (2019) 'Methodical Approach for Process Selection in Additive Manufacturing', in Proceedings of the 22nd International Conference on Engineering Design (ICED19), Delft, The Netherlands, 5-8 August 2019. DOI:10.1017/dsi.2019.82 


\section{INTRODUCTION}

The outstanding market potential of additive (or generative) manufacturing (AM) is based on increasing technological maturity and decreasing costs. Since the first functional plant was built in 1984, additive manufacturing has been used almost exclusively for special industrial applications, e.g. rapid prototyping. In recent years, rapid technical progress has led to additive manufacturing reaching a high level of technological maturity, which enables a wide range of applications, e.g. the direct production of end products (rapid manufacturing) (Commission of Experts for Research and Innovation EFI 2015).

In fields such as the aerospace industry, prototype construction and medical technology, additive manufacturing is state-of-the-art. Brandis et al. (2016) state that additive manufacturing technologies have reached the necessary level of maturity to be used in machine and plant construction. The advantages of AM are geometrically complex parts, small quantities and fast reaction times. The use of AM technologies also adds value for the customer by generating individualized products (Spallek and Krause, 2017). However, the lack of knowledge about the different process technologies often leads to a variety of different errors:

1. The potential of AM has not been evaluated sufficiently. Small to medium-sized enterprises (SMEs) lack the resources to independently build up knowledge on possible benefits, application potential, new product design requirements associated with additive manufacturing, and profitable use (e.g. design guidelines, solution knowledge, and methods for cost/effort estimation). The identification of potential is essential to the successful implementation of additive manufacturing. The focus here is on the one hand on functional integration, i.e. which functions, functional and design elements can be implemented in a product, and on the other hand on the identification of suitable products. It is often unclear to inexperienced developers when to use additive manufacturing over classical machining.

2. AM technologies are often tested on conventional components. This is usually uneconomical and ineffective, since the process advantages of additive technologies are not used. The necessary knowledge is often missing in the design process. Established design methods are not easily applicable to the use of additive manufacturing technologies. Procedures and rules, such as design principles, are created for "classic design"; only a few holistic guidelines, like Adam (2015), have been developed for AM technologies.

3. Individual process restrictions of AM technologies are not considered. Each AM technology has like every other production technology - benefits and restrictions to product design (wall thicknesses, draft angles, edge radii, materials, etc.). Considering that no technology can deliver a solution for every product requirement, the need for a holistic technology selection method becomes apparent.

This paper presents a validated methodical approach that supports designers at an early stage of product development. The aim of this approach is to support the analysis, product design and process selection for additive manufacturing, based on the individual product portfolio of a company. Therefore, part classes, based on the company portfolio, are derived. These classes are linked with available production technologies (additive and conventional) for their class-individual requirements. Design guidelines and a costing systematic are implemented.

Section 2 of this paper provides a brief survey of additive manufacturing methods and technologies, including a description of the main processes, their advantages and disadvantages, and the current state of existing methodological approaches to the development of additively manufactured parts. The new approach will be introduced and explained in Section 3. Section 4 contains the case study that validates the approach, followed by the outlook for future research in Section 5.

\section{ADDITIVE MANUFACTURING - BACKGROUND}

A remarkable characteristic of additive manufacturing is the diversity of production processes. The term 'additive manufacturing processes' covers all processes that generate a desired geometry by joining volume elements. AM processes are used both in the production of samples and prototypes (rapid prototyping) and in the manufacture of products (rapid manufacturing). Tools and tool inserts (rapid tooling) can also be created (Breuniger et al., 2013).

The shaping of all AM processes takes place in the xy-plane and is therefore two-dimensional. Threedimensionality is created by joining individual layers of the same thickness together along the z-axis. 
AM processes can be divided into the two sub-steps: generating a layer and joining a layer with the previous layer. This procedure means that the procedure corresponds strictly to a $2 \frac{1}{2} \mathrm{D}$ procedure (Gebhardt 2016).

\subsection{Classification of additive manufacturing processes}

For generative manufacturing there is a multitude of possible methods. They are differentiated by the state of aggregation, the type of starting material and the technological principle of model creation. Figure 1 illustrates classification of the differentiation of additive manufacturing processes according to DIN 8580, which was established for systematic consideration of generative processes.

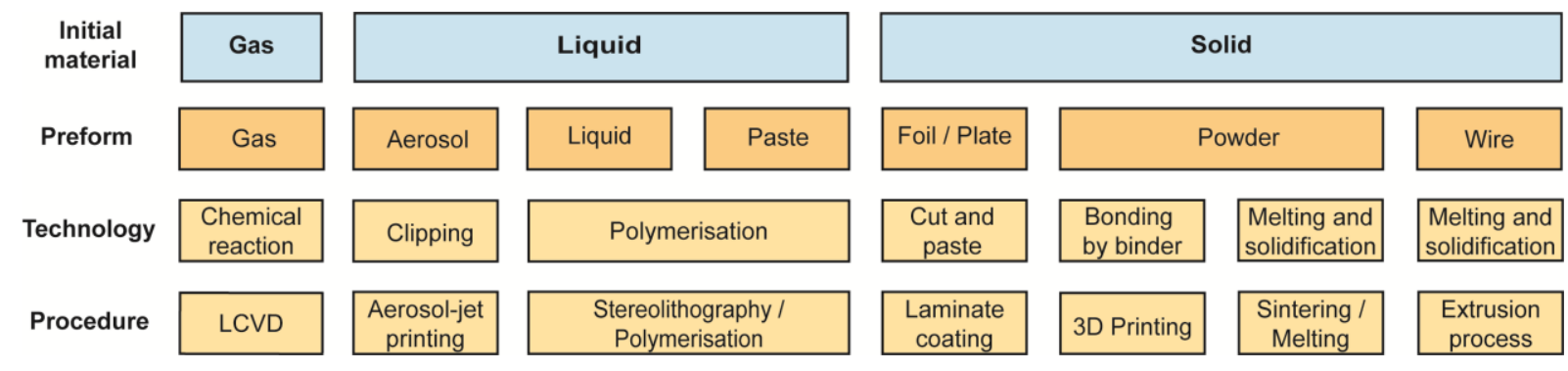

Figure 1. Differentiation of additive manufacturing processes according to DIN 8580

In the first instance, a distinction is made according to the aggregate state of the starting material. The second level of classification is classified according to the form of appearance in the sense of a semifinished product. The third level shows the mechanism of layer generation and the fourth level contains the generic name of the process. From the large variety of different processes (especially for polymers), the AM processes stereolithography (STL), selective laser sintering/melting (SLS/SLM), and fused layer modelling (FLM) are the production procedures that are most likely to be used in series production in an industrial environment. These processes differ in their geometrical freedom, stability, accuracy and building speed; this has a huge impact on product design and process selection (Gebhardt 2016).

\section{Challenges with additive manufacturing processes}

One of the greatest challenges in AM processes is the interaction between production time, mechanical stability, and maximum achievable accuracy. This interaction depends on the selected process and the machine connected to it, e.g. higher accuracy can be achieved with STL than with FLM, whereas SLS parts can be more stable. The desired and selected layer thickness is also decisive for product quality. The smaller the layer thickness, the more accurately a product can be manufactured. This in turn increases the time required.

Since the introduction of the first stereolithography systems, many other generative processes have been developed. These have different restrictions in their mechanical and thermal properties as well as their accuracy and post-processing effort. As a general rule, the production restrictions of the individual processes have a direct effect on the product shape. Thus, CAD models of a product for a certain procedure are not easily transferable to another procedure (Breuniger et al., 2013).

\subsection{Methods for process selection in additive manufacturing}

Due to the many dependencies between product requirements and individual process restrictions in the product development process, production system planning must take place at an early stage. Usually, product design and material, number of units to be produced, and other technological and economic criteria are considered. Due to the influence of design, material and production technology, their determination is characterized by a complex interplay of the individual influencing variables and several iterations. The selection is largely dependent on the experience and manufacturing knowledge of the developer (Fallböhmer 2000). According to Steimer et al. (2016), selection of the appropriate production technology needs to be made at the beginning of the planning process. There are a number of computer-aided methods to assist the developer in the selection process. The most well-known approach is Materials and Process Selection in Mechanical Design by Michael F. Ashby (2005), whose systematics was converted into a software tool. However, the required input information is 
sometimes very detailed and therefore not suitable for early use. The same applies to the solutions of Zah (2005) and Zarandi et al. (2011).

Some methods can be found in the literature in connection with part identification and/or process selection for AM. Gebhardt (2016) offers a comprehensive book on additive manufacturing. It provides definitions and describes the characteristics, the different processes, machines and economic aspects. The selection of suitable additive manufacturing processes is listed under economic efficiency. He highlights an individual list of requirements as the basis for selection. The influencing variables of the processes, their possibilities and limits, as well as part properties are mentioned as further elements of selection, whereby reference is made to the specific chapters in the book (Gebhardt 2016). A methodical procedure for the selection of manufacturing processes is not provided. Conventional methods are not considered in the selection.

In the book "Methodical Design of Additively Manufactured Components", Kumke (2018) presents an adapted design methodology for additive manufacturing processes. He introduces a decision node into VDI 2221, in which AM experts in process selection should be involved. He develops a flexible and generic method for part identification and selection. This method is divided into four steps: preparation, screening, evaluation and selection. In the first phase, the aim is defined, stakeholders identified and informed, and parts data collected. In the screening phase, as many potentially suitable parts as possible are collected. A list of guiding questions and methods is provided. In the evaluation phase, pre-selection of the potentially most suitable parts is made, AM experts are involved, and evaluation carried out. In the final phase, the selection process, and profiles of the most highly rated parts from phase 3 are prepared, discussed with the stakeholders and selected (Kumke 2018). In this procedure, the best-valued parts are described in profiles, and are not based on part classes.

Lindemann et al. (2015) provide a method for identifying suitable parts for AM, along with approaches to redesign parts and economic impacts. It is based on a workshop concept and is divided into the three main phases information, assessment and decision. In the information phase, the advantages, restrictions and design guidelines of AM are shown. After the first phase, the user is able to select several sample parts and classify them in a trade-off methodology matrix (TOM). The parts are evaluated in the assessment phase with the help of AM experts and part owners. Afterwards, in the decision phase, further information is collected in "InformationForms" and a selection of parts is made based on this information (Lindemann et al., 2015).

Yim and Rosen (2012) describe a model that, based on approximate geometric information about the part (e.g. size and volume), allows a cost and construction time estimation, which results in a recommendation for a suitable AM process.

Schmidt (2016) provides a method for evaluating additively manufactured parts that can be used to make a part-specific overall economic assessment. Criteria for part selection, such as individualization, geometric complexity and quantity, are provided, which leads to potential lightweight construction, function and cost/time. The method focuses on part weight estimations in order to leverage lightweight potential. The specific parts characteristics of the manufacturing processes are used to evaluate the three mentioned potential. The areas of potential are combined to assess overall economic efficiency and additional effects are taken into consideration. In the step 'process selection', one additive and two conventional methods for process selection are compared, based on a preliminary comparison of different manufacturing processes in aviation (Schmidt 2016).

The methods available in the literature are more oriented towards the identification of suitable parts for AM and often do not distinguish between the specifics of the different processes. In addition, some methods do not take conventional methods into account when selecting a manufacturing process, remain too generic, depend on the involvement of AM experts or focus strongly on an area of application (e.g. spare parts business, lightweight construction, etc).

\section{METHODICAL APPROACH FOR PROCESS SELECTION IN ADDITIVE MANUFACTURING}

The general suitability of a part for additive manufacturing and the subsequent process selection are complicated development tasks. The basis of any product development is primarily the question of basic technical feasibility. With technical systems, it is less a matter of identifying scientific limits than of ensuring the technical manufacturability of a product idea. From an almost infinite number of possible processes, those processes with which the corresponding product idea can be optimally 
produced must be selected. Product characteristics must be linked with process restrictions and unsuitable process steps need to be eliminated.

A methodical approach was developed in an eight-month project with a mid-sized company. The aim was to enable the company to systematically select manufacturing processes to produce customerspecific parts, focusing on the differentiation between conventional and additive manufacturing processes. A four-stage process was applied.

\subsection{Stage 1: Identification of applications and processes}

In this first stage, the specific offer process of the company was considered and the point at which the decision whether to choose additive manufacturing was determined and integrated into this process. The offer process was analysed and experts of the company were interviewed. The phase of drawing examination was worked out as the decision point for AM technology use in the company, as design adaptions to the selected manufacturing process (design for manufacturing) are feasible in this phase. Jürgenhake and Dumitrescu (2016) pointed out that different constructional elements have a huge impact on the suitability of manufacturing processes. Based on this, the product range was analysed and, in cooperation with the company, part characteristics were identified which were used when choosing a manufacturing process. These part characteristics are described by their specific attributes. With the aim of forming part classes, the attributes were analysed for their consistency, according to phases 3 and 4 of the method VITOSTRA (Method for developing consistent strategy options) (Bätzel 2004). Figure 2 shows an extract from the consistency matrix, in which the consistency of eleven characteristics with their specific attributes were checked.

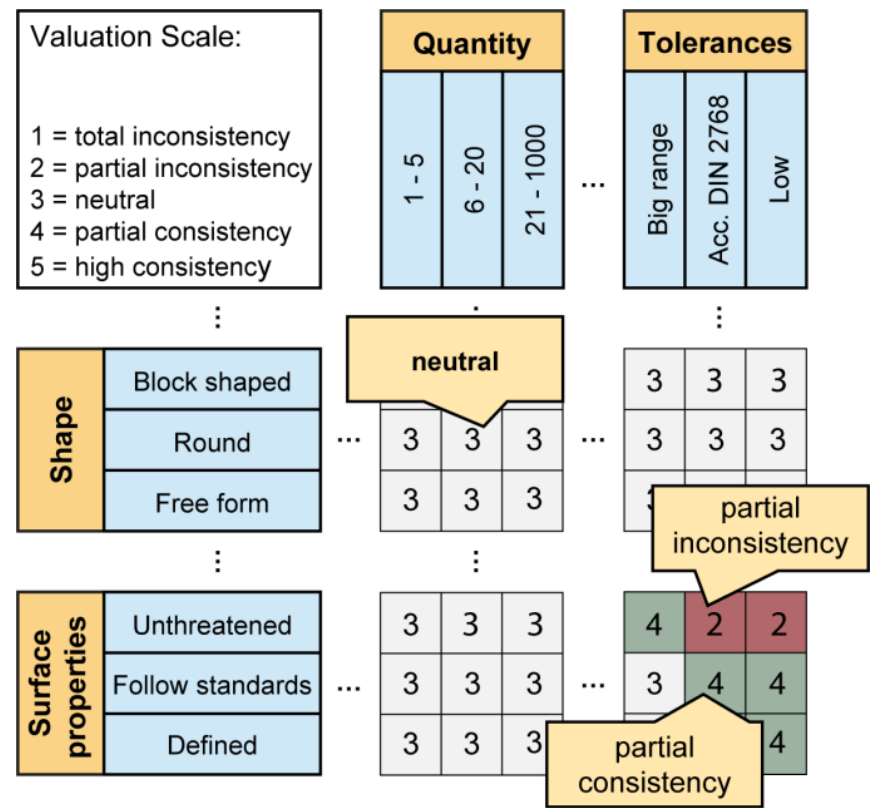

Figure 2. Extract from the consistency matrix, with part characteristics and specific attributes

An evaluation of this consistency analysis was performed with the software 'Permap', resulting in several consistent part classes. Figure 3 shows four derived consistent part classes in a multidimensional space. The part classes differ from each other in eleven characteristics: shape, application, quantity, part volume, surface properties, tolerances, functional elements, shape elements, planes, surface form, material properties and conventional producibility. The part classes were described in the form of fact sheets. 


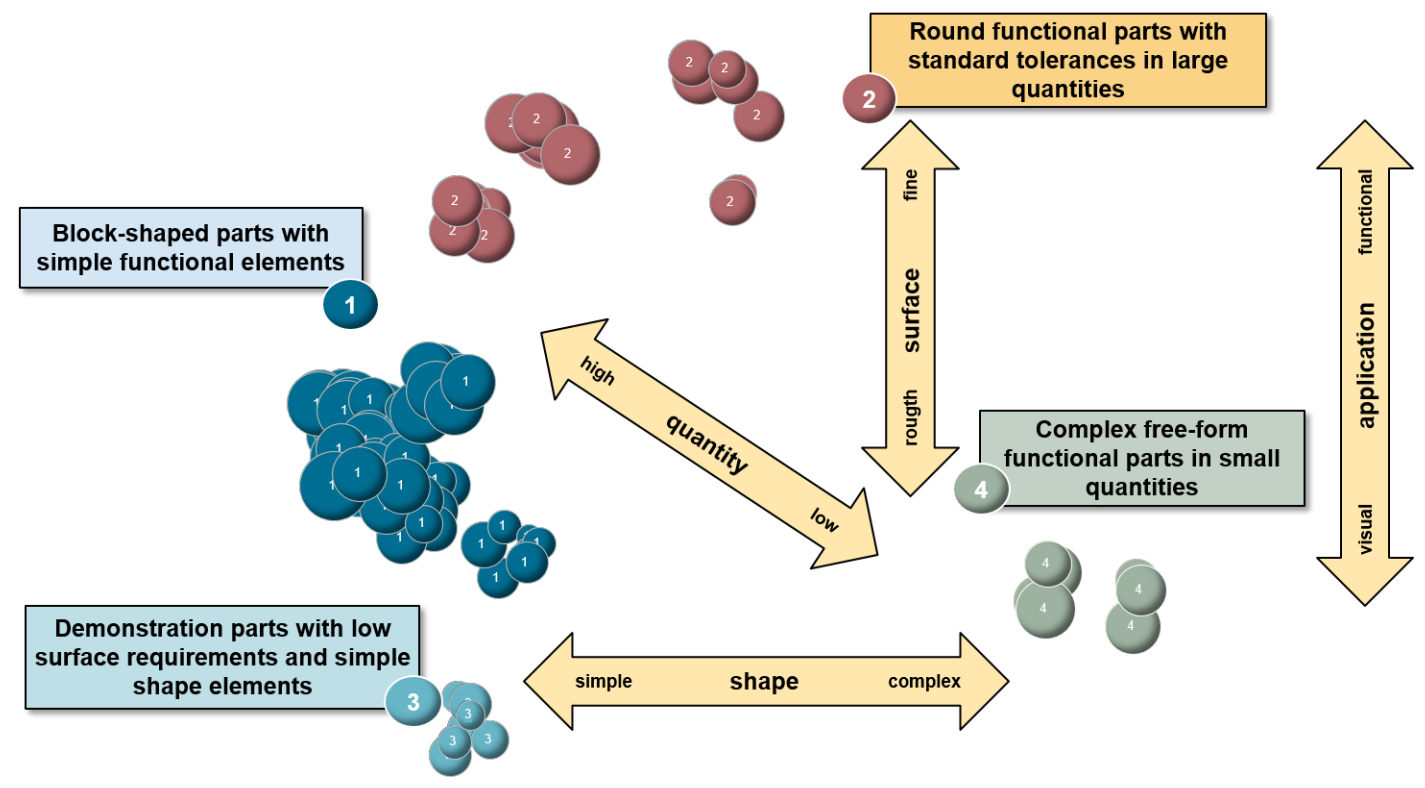

Figure 3: Part classes derived from the consistency analysis, represented by multidimensional scaling

In the next step, the manufacturing processes available to the company are evaluated for part class characteristic attributes. This applies not only to additive processes but also to classic subtractive manufacturing processes. For evaluation, a percentage weighting along the characteristic attributes is carried out for each manufacturing process. This allows the manufacturing processes to be matched with the part classes determined. The investigated manufacturing processes are at varying distances from the part class. The smaller the distance between the part class and the manufacturing process, the more suitable for manufacturing the specific part class is.

\subsection{Stage 2: Encouragement of additive thinking}

Additive thinking is essential to the success of implementation and introduction of additive technologies. Therefore, in the second stage, the company is provided with tailored processes, methods and design guidelines that suit their typical product development and adaption processes. The selection process needed to be implemented in the typical offering process. For this purpose, the process was analysed and a decision tree set up that supplements typical procedures with production analysis and potential redesign steps. To support the sales representative, indicators based on the four main decision characteristics of surface, shape, quantity and application, were developed that allow quick assessment of a product enquiry. The engineers trained in classic production processes were supported with tailored design guidelines, overviews of the advantages and disadvantages of additive manufacturing, and fact sheets for the various additive manufacturing technologies. A diagram was developed that characterizes polymers by density and young's modulus in order to determine similarities between familiar materials and specifics for additive manufacturing available materials (like Ashby's young's modulus - density diagrams).

The guidelines facilitate acceptance of additive manufacturing in the company and encourages an additive thinking mindset within the people involved.

\subsection{Stage 3: Cost estimation}

A simplified cost model was developed in this phase to compare the manufacturing costs of conventionally manufactured and additively manufactured parts. Figure 4, upper half, shows the relevant parameters for the calculation of costs during the three main AM phases of preparation, additive process and post processing. The set-up time, parts preparation time, and the duration of product variation depend on the geometry and must therefore be estimated (Ott 2012). The lower half of Figure 4 shows the calculations for each main phase of the additive manufacturing process, including the machine hour rate, process costs, and material costs. 


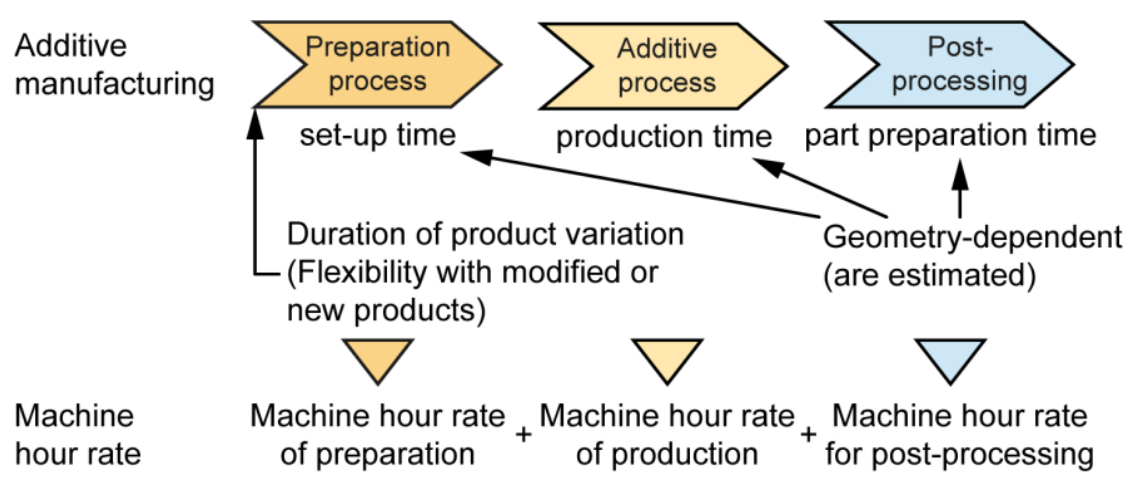

Figure 4. Simplified cost model for estimating the costs of additively manufactured parts (in reference to Ott 2012)

\subsection{Stage 4: Development of the process model for process selection in additive manufacturing}

In the last stage, a process model (Figure 5) is derived that enables companies to systematically select a suitable production process on the basis of the part classes developed in the first stage.

Phase / Milestone

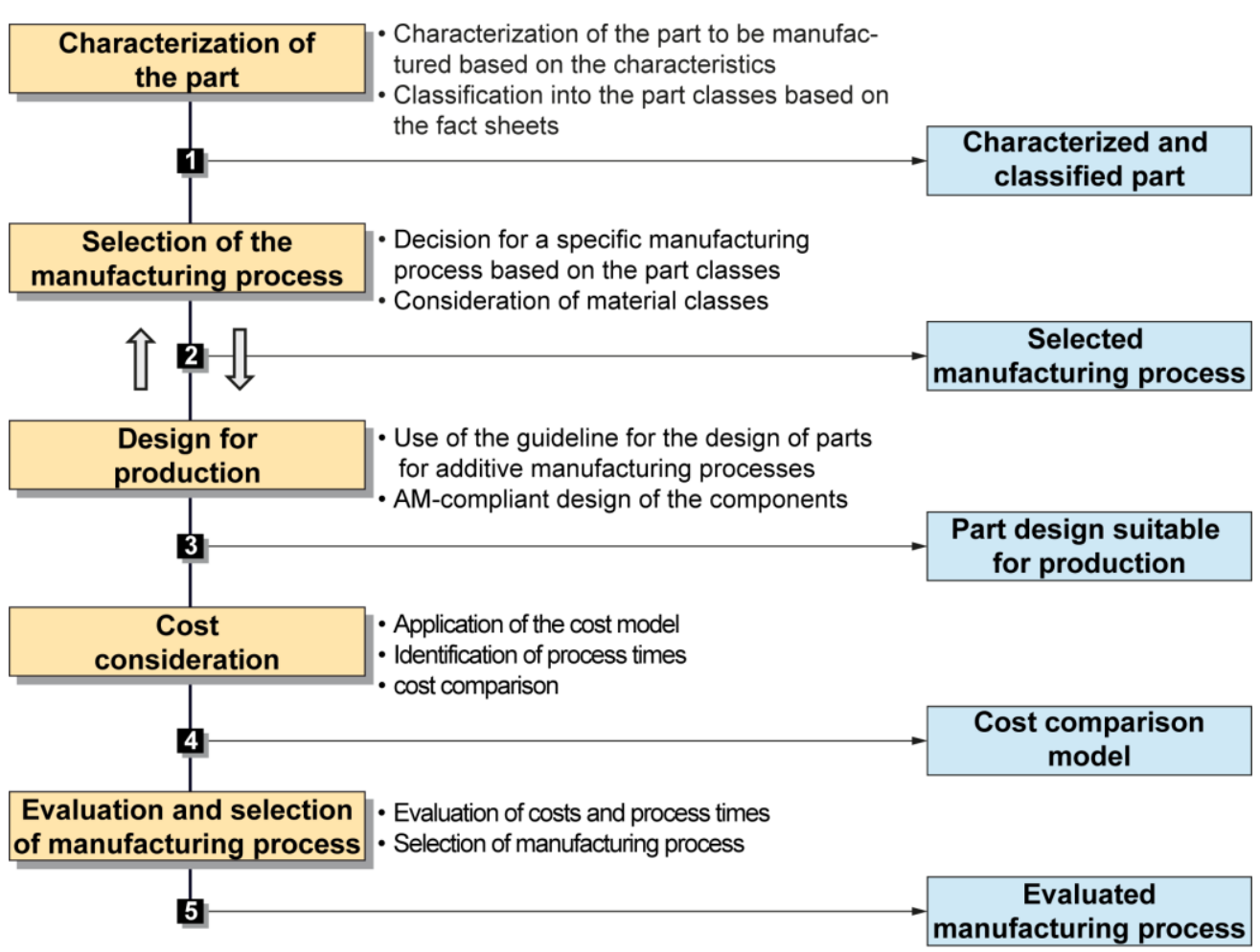

Figure 5. Process model for the systematic selection of a manufacturing technology considering the potential of additive manufacturing

The process model starts when a part is ordered by the company. In the first phase, the part is characterized based on the defined part attributes and then classified into one of the defined part classes. In the second phase, a suitable manufacturing process is selected based on part class fact sheets. The selection of manufacturing processes is integrated with phase 3 for the design for production. Any manufacturing restrictions regarding part geometry can thus be directly considered. The developed guideline (Stage 2) can be used to carry out an AM-compliant design of the part. Cost estimation of the part to be manufactured is the main objective of phase 4 . The costs can be estimated using the simplified cost model shown in Stage 3. Costs and production times are evaluated and final assessment of the manufacturing process selection is carried out. 
With the help of the process model, the company is capable of evaluating customer enquiries about the feasibility of using additive manufacturing technologies, systematically analysing possible processes, making appropriate design adjustments, and comparing costs with conventional manufacturing technologies at an early stage.

\section{CASE STUDY}

The process model has been validated in several projects with industrial partners. In order not to violate any confidentiality agreements, a brief overview of an internal company use case is given below without specifically explaining any customer project. The key question was the extent to which additive manufacturing can replace existing classical product manufacturing.

\subsection{Phase 1: Characterization of the part}

Within the first phase of the process model, the parts portfolio of the company was structured to generate different classes of parts. For AM generally, complex parts in very small quantities are the most promising. For this reason, this class was examined. The aspects used were fitted to the data available in the ERP system of the company and assessed for additive manufacturing. The following aspects were considered:

- Whether the parts are ordered at a supplier or produced in house. If the former is the case, there is only information about lead-time, price and quantity and, in many cases, weight at delivery available. If the latter, much more highly relevant information is accessible to aid the decision on which manufacturing process is best suited to optimize the general outcome. An important piece of information here is how the part price is composed of machine time and machine costs. Internally produced parts provide better information and it is to directly change the production method. Therefore, only internal produced parts were reviewed.

- Production process data were analysed to determine the number of units needed, as well as the geometrical shape of the part and, in most cases, the material. Some manufacturing processes are unlikely to be replaced by AM, e.g. forging, casting, and injection moulding, as they are all processes for manufacturing large quantities.

- Geometrical and functional complexity of the parts were analysed. In most cases, design engineers try to keep complex parts to a minimum though sometimes it is not possible due to overall system requirements. In subtractive production more advanced machines are needed to produce such parts and to lower machining times, e.g. multis-axis milling machines or injection moulding tools with slides. Here, weight data has an important function in generating a key figure, together with machine time, to describe the complexity of parts based on the metadata: The lower the weight of a part after machining and the longer the machining time on an expensive system, the more complex the part.

The evaluated and selected part was an assembling tool that assists with screwing a cover onto a finished product. The cover is a not symmetric part and the tool has free-form surfaces. Only low forces have to be applied. The current production process consists of milling the free-form part and a grip, cutting of a connector, and the final gluing process.

\subsection{Phase 2 and 3: Selection of the manufacturing process and design for production}

Considering the evaluated fact sheet for the part classes, manufacturing process can be selected for manufacturing of the selected part. Figure 6 shows an extract of an example profile for "complex freeform functional part in low quantities", to which the selected part fits. The most suitable production processes for this class are STL, SLS, FLM and Multi-Jet-Modelling (MJM) (Figure 3). MJM was not considered as it was not available in the company. With the help of the derived design guidelines, initial estimates of the viability of each production process could be made. With the developed material overview and a first draft of the possible materials, FLM was identified as the most promising process. 


\begin{tabular}{|c|c|c|c|}
\hline \multicolumn{3}{|l|}{ Part class 4} & Example \\
\hline \multicolumn{3}{|c|}{ Complex free-form functional part in low quantities } & \\
\hline \multicolumn{3}{|l|}{ Description } & \\
\hline \multicolumn{4}{|c|}{$\begin{array}{l}\text { This part class includes free-form functional parts with free-form surfaces that are manufactured in } \\
\text { small quantities ( } 1-5 \text { pieces). Most of the surfaces are to be produced according to standards. There } \\
\text { are high requirements with regard to tolerances. The functional elements are complex (e.g. screw } \\
\text { flight). The parts cannot be manufactured conventionally and also have complex shape elements, e.g. } \\
\text { internal structures or curved surfaces. With regard to the material properties, these requirements have } \\
\text { to do with chemical and temperature resistance as well as dielectric strength. }\end{array}$} \\
\hline Characteristics & \multicolumn{3}{|l|}{ Attributes } \\
\hline Shape & Block-shaped & circular & free-form \\
\hline Application & \multicolumn{3}{|c|}{ demonstrator } \\
\hline
\end{tabular}

Figure 6. Extract of fact sheet "complex free-form functional part in low quantities"

\subsection{Phase 4: Cost consideration}

Cost comparison of existing alternative classical production processes with the identified additive technologies was carried out. Figure 7 shows that FLM was again better compared to other production processes. Due to the low demands for surface quality, simple low-cost systems could be used. In this case, a standard Ultimaker 2+ was used for production, lowering investment costs and machine hours significantly in contrast to classic cutting processes (calculated on a machine lifetime of $2000 \mathrm{~h}$ ).

\begin{tabular}{|l|l|c|c|c|c|c|}
\hline Process & $\begin{array}{l}\text { Formulal } \\
\text { Fomel character }\end{array}$ & unit & STL & SLS & FLM & Mil \\
\hline Preparation & $\mathrm{K}_{\mathrm{V}, \text { Ges }}$ & $€$ & - & - & - & 40,00 \\
\hline Production & $\mathrm{K}_{\mathrm{F}, \text { Ges }}$ & $€$ & 117,13 & 59,76 & 6,35 & 235,00 \\
\hline Post-pro. & $\mathrm{K}_{\mathrm{N}, \text { Ges }}$ & $€$ & 4,50 & 4,50 & 8,00 & 65,00 \\
\hline Total costs & $\mathrm{K}_{\text {ges }}=\mathbf{K}_{\mathrm{V}, \text { Ges }}+\mathbf{K}_{\mathrm{F}, \text { Ges }}+\mathrm{K}_{\mathrm{N}, \text { Ges }}$ & $€$ & 121,63 & 60,26 & 14,35 & 340,00 \\
\hline
\end{tabular}

\begin{tabular}{|c|c|}
\hline \multicolumn{2}{|c|}{ Processes } \\
\hline STL & Stereolithography \\
\hline SLS & Selective Laser Sintering \\
\hline FLM & Fused Layer Modeling \\
\hline Mil & Milling semi-finished parts \\
\hline
\end{tabular}

Figure 7. Cost comparison of production processes for the selected part

\subsection{Phase 5: Evaluation and selection of manufacturing process}

The systematic selection of the reference part and the appropriate production technology as well as the cost comparison led to the selection of FLM as a new production process. Other additive manufacturing technologies can supplement a company production portfolio and must be considered more intensively. In the case of higher surface quality demands or component stability, further processes can be a meaningful addition. For this reason, the following is recommended:

- Operational: FLM can be used as an additive process for most parts of part class.

- Tactical: The extension by STL will improve the quality of class 4 products in the medium term.

- Strategic: In the long term, add additive processes, such as SLS, to further exploit potential (higher degree of functional integration, etc). With increasing numbers of units, the currently critical share of production costs (which results from the high cost of the plant) decreases.

\section{CONCLUSION}

Additive manufacturing is a key aspect of the modern industrial environment. Because its degree of digitalisation is very high it could be a game changer in the race to Industry 4.0 or smart factories. Topics like the internet of things or big data are more easily accessible when an additive production process is embedded in a company. Compared to conventional production systems no big changes in production systems are necessary, meaning fewer interruptions during implementation. This demonstrates the strategic need to implement AM in company business. Although AM is not yet profitable for every business model, the disruptive potential of additive manufacturing will provide a strong competitive advantage in the future for anyone with experience of the technologies. The methodical approach enables smaller companies in particular to exploit the potential of additive manufacturing. 


\section{REFERENCES}

Adam, G. (2015), "Systematische Erarbeitung von Konstruktionsregeln für die additiven Fertigungsverfahren Lasersintern, Laserschmelzen und Fused Deposition Modeling”, Dissertation, Universität Paderborn, Shaker, Aachen.

Ashby, M. F. (2005), Materials Selection in Mechanical Design, Elsevier Butterworth-Heinemann, Oxford, https://doi.org/10.1016/b978-1-85617-663-7.00002-3

Bätzel, D. (2004), Methode zur Ermittlung und Bewertung von Strategievarianten im Kontext Fertigungstechnik, Dissertation, Faculty of Mechanical Engineering, University of Paderborn, HNI Publishing Series, Vol. 141.

Brandis, R., Wanzek, A.-L., Schneider, M., and Gausemeier, J. (2016), "Integration additiver fertigungstechnologien in die produktentstehung", Zwf Zeitschrift für Wirtschaftlichen Fabrikbetrieb, Vol. 111 No. 11, pp. 718-722, https://doi.org/10.3139/104.111615

Breuniger, J., Becker, R., Wolf, A., Rommel, S. and Verl, A. (2013), Generative Fertigung mit Kunststoffen: Konzeption und Konstruktion für Selektives Lasersintern, Springer Vieweg, Berlin, https://doi.org/10.1007/978-3-642-24325-7_3

Commission of Experts for Research and Innovation (EFI) (2015), Research, innovation and technological performance in Germany - EFI Report 2015, EFI, Berlin.

Fallböhmer, M. (2000), "Generieren alternativer Technologieketten in frühen Phasen der Produktentwicklung", Dissertation, Rheinisch-Westfälische Technische Hochschule Aachen, Shaker Verlag.

Gebhardt, A. (2016), Additive Fertigungsverfahren. Additive Manufacturing und 3D-Drucken für PrototypingTooling - Produktion, 5th, revised and extended edition, Carl Hanser Verlag GmbH \& Co. KG, Munich. https://doi.org/10.3139/9783446445390

Jürgenhake, C. and Dumitrescu, R. (2016), "Systematic for function-oriented development of spatial integrated circuit carriers", Proceedings of International Design Conference, DESIGN Volume DS 84, 2016, Pages 1657-166814th International Design Conference, DESIGN 2016; Cavtat, Dubrovnik; Croatia; 16 May 2016 through 19 May 2016; Code 122424

Kumke, M. (2018), Methodisches Konstruieren von additiv gefertigten Bauteilen, AutoUni-Schriftenreihe Vol. 124, Volkswagen Aktiengesellschaft, Springer Fachmedien, Wiesbaden. http://dx.doi.org/10.1007/978-3658-22209-3

Lindemann, C., Reiher, T., Jahnke, U. and Koch, R. (2015), “Towards a sustainable and economic selection of part candidates for additive manufacturing”, Rapid Prototyping Journal, Vol. 21 No. 2, pp. 216-227. https://doi.org/10.1108/RPJ-12-2014-0179

Ott, M. (2012), "Multimaterialverarbeitung bei der additiven strahl- und pulverbettbasierten Fertigung", Dissertation, Technical University of Munich Department of Machine Tools and Production Engineering. http://nbn-resolving.de/urn/resolver.pl?urn:nbn:de:bvb:91-diss-20120703-1095129-1-6

Schmidt, T. (2016), Potentialbewertung Generativer Fertigungsverfahren für Leichtbauteile, Springer Vieweg, Berlin. https://doi.org/10.1007/978-3-662-52996-6

Spallek, S. and Krause, D. (2017), Entwicklung Individualisierter Produkte durch den Einsatz Additiver Fertigung, In: Lachmayer, R. and Lippert, R.B. (Ed.), Additive Manufacturing Quantifiziert, SpringerVerlag, Berlin, pp. 69-83. http://doi.org/10.1007/978-3-662-54113-5_5

Steimer, C., Cadet, M., Aurich, J. and Stephan, N. (2016), “Approach for an integrated planning of manufacturing systems based on early phases of product development", 49th CIRP Conference on Manufacturing Systems, CIRP Vol. 57, S. pp. 467-472, https://doi.org/10.1016/j.procir.2016.11.081

Yim, S. and Rosen, D. (2012), "Build Time and Cost Models for Additive Manufacturing Process Selection", ASME 2012 International Design Engineering Technical Conferences and Computers and Information in Engineering Conference, Chicago, Illinois, USA, August 12-15, 2012, Paper No. DETC2012-70940, pp. 375-382. http://doi.org/10.1115/DETC2012-70940

Zha, X.F. (2005), A Web-Based Advisory System for Process and Material Selection in Concurrent Product Design for a Manufacturing Environment, The International Journal of Advanced Manufacturing Technology Vol. 25, Springer, London, https://doi.org/10.1007/s00170-003-1838-0

Zarandi, M. H. F., Mansour, S., Hosseinijou, S. and Avazbeigi, M. (2011), “A material selection methodology and expert system for sustainable product design", The International Journal of Advanced Manufacturing Technology, Vol. 57 No. 9, pp 885-903, https://doi.org/10.1007/s00170-011-3362-y

\section{ACKNOWLEDGMENTS}

Thank you to the German Federal Ministry of Education and Research (BMBF) for funding part of this research and development project within the Leading Edge Cluster, "Intelligent Technical Systems OstWestfalenLippe" (it's OWL), managed by the Project Management Agency Karlsruhe (PTKA). The author is responsible for the contents of this publication. 